\title{
Estimation of Rock Physical Parameters Based on Digital Rock Physics Image, Case Study: Blok Cepu Oil Field, Central Java, Indonesia
}

\author{
Estimasi Parameter Fisis Batuan Berdasarkan Citra Batuan (Digital Rock Physics) Studi Kasus:
}

\author{
Lapangan Minyak Bumi Blok Cepu, Jawa Tengah, Indonesia
}

\author{
Handoyo $^{1 *}$, Fatkhan ${ }^{2}$, Fourier Dzar Eljabbar Latief $^{3}$, Reza Rizki ${ }^{1}$, Harnanti Yoga Putri ${ }^{1}$ \\ ${ }^{1}$ Teknik Geofisika, Institut Teknologi Sumatera, Lampung, Indonesia \\ ${ }^{2}$ Teknik Geofisika, Fakultas Teknik Pertambangan dan Perminyakan, ITB, \\ Jalan Ganesa No. 10, Bandung 40132, Indonesia \\ ${ }^{3}$ Kelompok Keahlian Fisika Bumi dan Sistem Kompleks, Fakultas Matematika dan Ilmu Pengetahuan Alam, ITB, \\ Jalan Ganesa No. 10,Bandung 40132, Indonesia
}

Submit 15-02-2018; Revised 27-02-2018; Accepted 03-03-2018

\begin{abstract}
Modern technique to estimate of the physical properties of rocks can be done by means of digital imaging and numerical simulation, an approach known as digital rock physics (DRP: Digital Rock Physics). Digital rock physics modeling is useful to understand microstructural parameters of rocks (pores and rock matrks), quite quickly and in detail. In this paper a study was conducted on sandstone reservoir samples in a rock formation. The core of sandstone samples were calculated porosity, permeability, and elasticity parameters in the laboratory. Then performed digital image processing using CT-Scan that utilizes Xray tomography. The result of digital image is processed and done by calculation of digital simulation to calculate porosity, permeability, and elastic parameter of sandstones. In addition, there are also predictions of p-wave velocity and wave - $S$ using the empirical equations given by Han (1986), Raymer (1990), and Nur (1998). The results of digital simulation (DRP) in this study provide a higher than the calculations in the laboratory. The digital rock physics method (DRP) combined with rock physics modeling can be a practical and rapid method for determining the rock properties of tiny (microscopic) rock fragments
\end{abstract}

Keywords: sandstone, rock physics, porosity, permeability, elasticity parameters

Abstrak: Estimasi modern sifat fisis batuan dapat dilakukan dengan menggabungkan pencitraan digital dan simulasi numerik, pendekatan dikenal sebagai fisika batuan digital (DRP: Digital Rock Physics). Pemodelan fisika batuan digital bermanfaat untuk melihat parameter mikrostruktur dari batuan (pori dan matrks batuan) secara cepat dan detail. Dalam paper ini dilakukan penelitian pada sampel reservoir batupasir pada suatu formasi batuan. Sampel batupasir berupa data core dihitung nilai porositas, permeabilitas, dan parameter elastisitas di laboratorium. Kemudian dilakukan pengolahan citra digital menggunakan CT-Scan yang memanfaatkan X-ray tomografi. Hasil citra digital diolah dan dilakukan perhitungan simulasi digital untuk menghitung nilai porositas, permeabilitas, dan parameter elastisitas sampel batupasir. Selain itu, dilakukan pula prediksi kecepatan gelombang -P dan gelombang -S menggunakan persamaan empiris yang diberikan oleh Han (1986), Raymer (1990), dan Nur (1998). Hasil simulasi digital (DRP) pada penelitian ini memberikan nilai lebih tinggi dari perhitungan di laboratorium. Metode fisika batuan digital (DRP) yang dikombinasikan dengan pemodelan fisika batuan dapat menjadi metode yang praktis dan cepat untuk menentukan sifat batuan dari fragmen batuan kecil (mikroskopis)

Katakunci:batupasir, digital rock physics, porositas, permeabilitas, parameter elastisitas

\section{PENDAHULUAN}

Pemodelan fisika batuan adalah salah satu cara untuk memahami karakteristik dari batuan reservoar. Pemodelan fisika batuan didasarkan dari ketersediaan data baik dari data core maupun data log. Dengan mengetahui jenis batuan penyusun dari reservoir, dapat dilakukan pemodelan fisika batuan berdasarkan sifat elatisitas dari batuan. Pengukuran sifat elastis batuan dapat dilakukan secara langsung dan tidak langsung. Pengukuran secara langsung dapat dilakukan menggunakan data core dan data log dari pemboran sumur di lapangan. Sedangkan pemodelan batuan secara tidak langsung dapat diperoleh dari inversi data seismik dan pendekatan fisika batuan digital (DRP).

Perhitungan parameter fisik batuan saat ini dapat ditentukan dengan menggunakan simulasi komputer (digital). Simulasi digital dilakukan untuk membuat model atau memvisualisasikan perbedaan antara pori dan matriks batuan dan dapat digunakan untuk memprediksi nilai porositas, permeabilitas, konduktivitas listrik, densitas, dan parameter elastisitas batuan. Citra digital batuan dapat diperoleh dari pemindaian menggunakan CT-Scan dan dikombinasikan dengan digital software simulasi. Selain itu, citra digital 
Tabel 1. Hasil pengukuran laboratorium sampel batupasir

\begin{tabular}{|l|l|}
\hline Porositas $(\%)$ & 31,70 \\
\hline Permeabilitas $(\mathrm{mD})$ & 2800,00 \\
\hline Modulus Bulk $(\mathrm{GPa})$ & 4,08 \\
\hline Modulus Shear $(\mathrm{GPa})$ & 3,23 \\
\hline $\mathrm{Vp}(\mathrm{km} / \mathrm{s})$ & 1,73 \\
\hline $\mathrm{Vs}(\mathrm{km} / \mathrm{s})$ & 1,16 \\
\hline $\mathrm{Vp} / \mathrm{Vs}$ & 1,49 \\
\hline
\end{tabular}

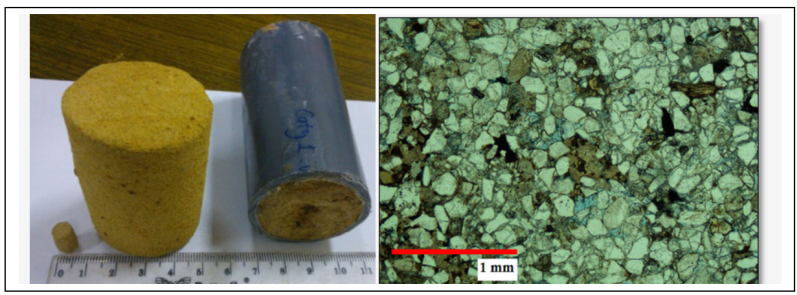

Gambar 1. Data core dan sayatan tipis sampel batupasir.

telah diterapkan untuk memvisualisasikan batuan dan memprediksi fisik parameter (misalnya, Arns dan Knackstedt, 2012; Dvorkin dkk., 2009; Handoyo dkk., 2014).

Paper ini membahas digital simulasi yang bertujuan untuk memvisualisasikan pori kompleks dan memprediksi nilai porositas, permeabilitas, modulus elastisitas, dan kecepatan gelombang seismik pada sampel batupasir. Juga dilakukan pengukuran di laboratorium dan persamaan empiris untuk memprediksi nilai kecepatan gelombang seismik (Han, 1986. Castagna, 1980, dan Nur, 1998).

\section{DATA DAN METODOLOGI}

\subsection{Data Penelitian}

Data penelitian adalah berupa sampel batupasir dekat permukaan sampai kedalaman sekitar 50 meter (out crop). Sampel batupasir adalah data core lapisan reservoir minyak yang tersingkap di permukaan. Hasil pengukuran laboratorium untuk sampel data core ditunjukkan oleh Tabel 1. Data sayatan tipis batuan menunjukkan bahwa sampel batupasir daerah penelitian didominasi oleh mineral kuarsa, feldspar, dan biotit (Gambar 1). Data fisis mineral-mineral tersebut ditunjukkan oleh Tabel 2.

\subsection{Teori Dasar}

Pada Gambar 1, nilai porositas $(\phi)$ dihitung dengan membandingkan volume pori terhadap volume total atau volume Bulk dari massa batuan yang dituliskan oleh persamaan:

$$
\phi=\frac{V_{\text {pore }}}{V_{\text {total }}}=1-\frac{V_{\text {matriks }}}{V_{\text {total }}}
$$

Permeabilitas merupakan sifat batuan reservoar yang dapat mengalirkan fluida melalui ruang antar pori. Permeabilitas bergantung pada porositas, dimensi dan geometri ruang pori sehingga permeabilitas memiliki sifat seperti ten- sor. Darcy merumuskan hubungan dasar untuk suatu aliran laminar fluida viskos yang melalui batuan berpori sebagai:

$$
Q=\frac{k A\left(P_{i}-P_{0}\right)}{\mu L}
$$

dimana, $Q$ adalah debit aliran fluida , $P_{0}$ adalah tekanan dari luar fluida, $P_{i}$ adalah tekanan di dalam pipa, adalah viskositas fluida, $\mathrm{k}$ adalah permeabilitas (Darcy), dan A adalah luas permukaan. Selanjutnya Kozeny-Carman memberikan hubungan antara porositas, permeabilitas, permukaan internal spesifik dan tortuositas sebagai (Dvorkin, 2009),

$$
k_{\text {absolute }}=\frac{1}{2} \frac{\phi^{3}}{S^{2} \tau^{2}}
$$

dengan $\phi$ adalah nilai porositas $S$ adalah luas permukaan internal spesifik dan $\tau$ adalah tortuositas. Sedangkan nilai kecepatan gelombang dirumuskan oleh persamaan:

$$
\begin{gathered}
V_{p}=\sqrt{\frac{\lambda+2 \mu}{\rho}}=\sqrt{\frac{K+\frac{4}{3} \mu}{\rho}} \\
V_{s}=\sqrt{\frac{\mu}{\rho}}
\end{gathered}
$$

Dimana $V_{p}$ adalah kecepatan gelombang $-P, V_{s}$ adalah kecepatan gelombang $-S, \rho$ adalah densitas batuan, $\kappa$ adalah modulus bulk, $\mu$ adalah modulus shear, $\lambda$ dan $\mu$ adalah parameter Lame. Secara empiris, Persamaan empiris yang menyatakan hubungan antara kecepatan dan porositas pada batuan sedimen tak termampatkan untuk dapat diperoleh dari beberapa persamaan empiris. Pada penelitian ini, persamaan empiris yang digunakan untuk menghitung kecepatan gelombang pada batuan ditunjukkan sebagai berikut:

- Raymer (1980)

$$
\begin{gathered}
V_{p}=(1-\phi)^{2} V_{m}+\phi V_{f} \\
V_{s}=(1-\phi)^{2} V_{m} \sqrt{\frac{(1-\phi) \rho_{m}}{(1-\phi) \rho_{m}+\phi \rho_{f}}}
\end{gathered}
$$

- Han (1986)

$$
V_{p}=5,41-6,35 \phi-2,87 C
$$

$$
V_{s}=3,57-4,57 \phi-1,83 C
$$

- Tosaya dan Nur (1982)

$$
\begin{aligned}
& V_{p}=5,8-8,6 \phi-2,4 C \\
& V_{p}=3,7-6,3 \phi-2,1 C
\end{aligned}
$$

\subsection{Simulasi Digital}

Simulasi digital untuk menghitung parameter elastisitas batuan digunakan bantuan software geodict. Prinsipnya adalah 


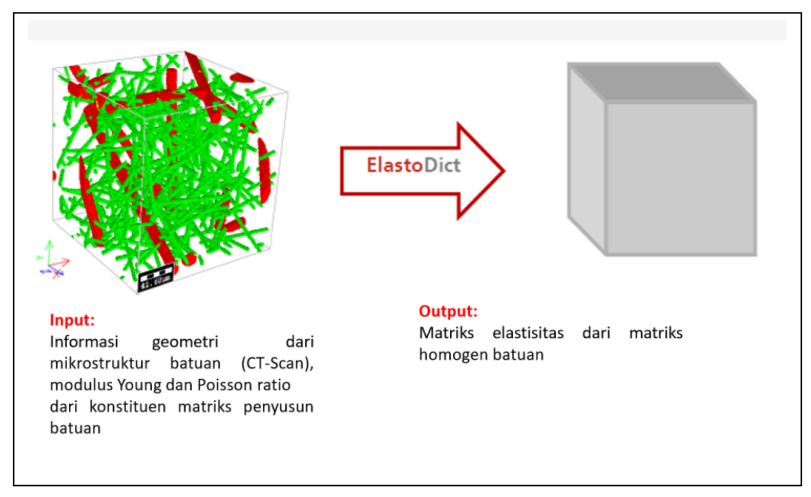

Gambar 2. Ilustrasi simulasi digital untuk memperoleh matriks tensor elastisitas sampel batuan (Wiegman, 2012).

Tabel 2. Hasil pengukuran laboratorium sampel batupasir

\begin{tabular}{|l|l|l|l|l|}
\hline Mineral & $\begin{array}{l}\text { Modulus } \\
\text { Bulk }\end{array}$ & $\begin{array}{l}\text { Modulus } \\
\text { Shear }\end{array}$ & $\begin{array}{l}\text { Modulus } \\
\text { Young }\end{array}$ & $\begin{array}{l}\text { Poisson } \\
\text { Ratio }\end{array}$ \\
\hline Udara & 0.00 & 0.00 & 0.00 & 0.50 \\
\hline Kuarsa & 37.00 & 44.00 & 94.53 & 0.06 \\
\hline Feldspar & 37.50 & 15.00 & 39.71 & 0.31 \\
\hline Biotit & 59.70 & 42.30 & 102.65 & 0.19 \\
\hline
\end{tabular}

memberikan data input Modulus Young dari tiap-tiap fraksi mineral penyusun batuan. Dengan menggunakan medan polarisasi stress dan mengubah medan strain menggunakan nonlocal elastic green operator 0 , maka dihasilkan persamaan Lippman Schwinger:

$$
\epsilon+\Gamma_{0} *\left(\left[C-C_{0}\right]: \epsilon\right)=E
$$

Persamaan diatas dihitung secara iteratif dengan Neumann series expansion. Dimana $C_{0}$ adalah material reference dari stiffness homogen, $\epsilon$ adalah strain, dan $\Gamma_{0}$ green operator. Persamaan tersebut dapat diselesaikan dalam domain Fourier ditransformasi fourier dengan FFT (Wiegman, 2012). Output dari persamaan tersebut adalah matriks tensor elastisitas:

$C_{\text {Isotope }}=\left|\begin{array}{cccccc}C_{11} & C_{12} & C_{12} & 0 & 0 & 0 \\ C_{12} & C_{11} & C_{12} & 0 & 0 & 0 \\ C_{12} & C_{12} & C_{11} & 0 & 0 & 0 \\ 0 & 0 & 0 & \frac{C_{11} \cdot C 12}{2} & 0 & 0 \\ 0 & 0 & 0 & 0 & \frac{C_{11} \cdot C 12}{2} & 0 \\ 0 & 0 & 0 & 0 & 0 & \frac{C_{11} \cdot C 12}{2}\end{array}\right|$

Ilustrasi simulasi digital pada penelitian ini ditunjukkan oleh Gambar 2. Sedangkan imput parameter untuk sampel batupasir pada penelitian ini diberikan oleh Tabel 2 .

\subsection{Diagram Alir Penelitian}

Data core sampel batupasir kemudian dibuat dalam bentuk citra digital menggunakan perangkat CT-Scan yang bekerja berdasarkan sifat sinar -X seperti di dunia kedokteran. Selanjutnya dari pengolahan digital tersebut diperoleh citra digital sampel batupasir dalam bentuk 2D (slice) dan kumpulan dari beberapa citra 2D akan membentuk citra
3D sampel batupasir. Selanjutnya nilai porositas, permeabilitas, dan kecepatan gelombang seismik dihitung menggunakan persamaan empiris dan simulasi digital. Urutan metodologi penelitian ditunjukkan oleh Gambar 3.

\section{HASIL DAN DISKUSI}

\subsection{Hasil Pengolahan Citra Digital}

Hasil pengolahan citra digital sampel batupasir pada penelitian ini ditunjukkan oleh Gambar 4. Pada Gambar 4a, pori batuan ditunjukkan oleh warna hitam, sedangkan matriks padat batuan ditunjukkan oleh warna abu-abu dan putih. Perbedaan warna tersebut berdasarkan perbedaan densitas dari masing-masing mineral. Gambar $4 \mathrm{~b}$ adalah citra mineral batuan yang memiliki densitas tertinggi.

\subsection{Perhitungan Nilai Parameter Fisis Sampel Batupasir}

Hasil perhitungan nilai porositas, permeabilitas, modulus elastisitas, dan kecepatan gelombang pada sampel batupasir ditunjukkan oleh Tabel 3. Perhitungan diperoleh dari hasil pengukuran laboratorium, persamaan empiris, dan simulasi digital.

Selanjutnya, untuk memperoleh nilai variasi dari parameter fisis sampel batupasir, dibuat beberapa sub-kubus dari kubus utama. Hasil pengolahan citra digital untuk beberapa sub-kubus ditunjukkan oleh Gambar 5. Hasil perhitungan dari masing-masing sub-kubus ditunjukkan oleh Tabel 4.

Variasi nilai permeabilitas sebagai fungsi porositas ditunjukkan oleh Gambar 6. Sedangkan variasi kecepatan gelombang sebagai fungsi porositas ditunjukkan oleh Gambar 7. Pada Gambar 7, kurva berwarna hijau adalah nilai kecepatan gelombang -P dan kurva berwarna kuning adalah nilai kecepatan gelombang $-\mathrm{S}$.

\subsection{Diskusi}

Reservoir batupasir adalah salah satu jenis reservoir yang paling banyak ditemukan. Jenis reservoir batupasir umumnya memiliki variasi nilai porositas dan permeabilitas cukup tinggi, sehingga sangat baik menjadi reservoir yang berkualitas baik. Hasil pada Tabel 4 menunjukkan bahwa sampel reservoir batupasir pada penelitian ini memiliki porositas sangat tinggi berkisar $30 \%$ dan permeabilitas relatif juga sangat tinggi berkisar $3000 \mathrm{mD}$.

Pada Tabel 4 diperoleh perbedaan hasil antara hasil simulasi digital dan pengkuran di laboratoium. Perbedaan hasil tersebut dapat disebabkan oleh perbadaan ukuran sampel yang digunakan. Pada pengukuran di laboratorium menggunakan data core dengan dimensi puluhan centimeter sedangkan pada simulasi digital menggunakan dimensi micrometer. Perbadaan skala/dimensi inilah yang memungkinkan terjadinya berbedaan hasil yang didapat.

Selanjutnya, hasil perhitungan pada beberapa subkubus menunjukkan bahwa parameter fisis sampel batupasir adalah bervariasi. Ini menunjukkan bahwa dimensi/ukuran dari sampel dapat mempengaruhi nilai/harga parameter fisis batuan. Dengan demikian, jika kita dapat memperoleh 


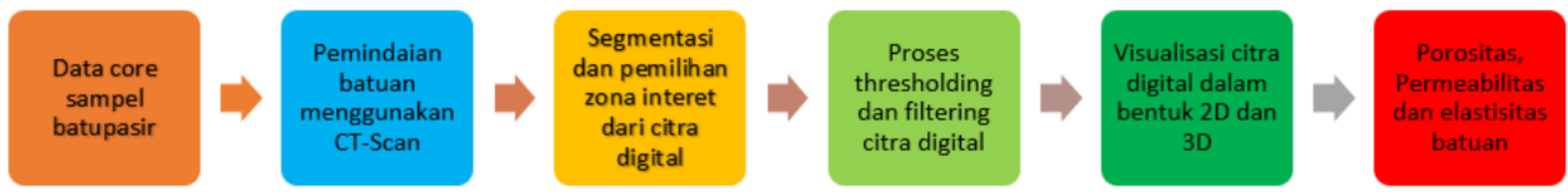

Gambar 3. Diagram alir penelitian pada sampel batupasir menggunakan pendekatan simulasi digital.

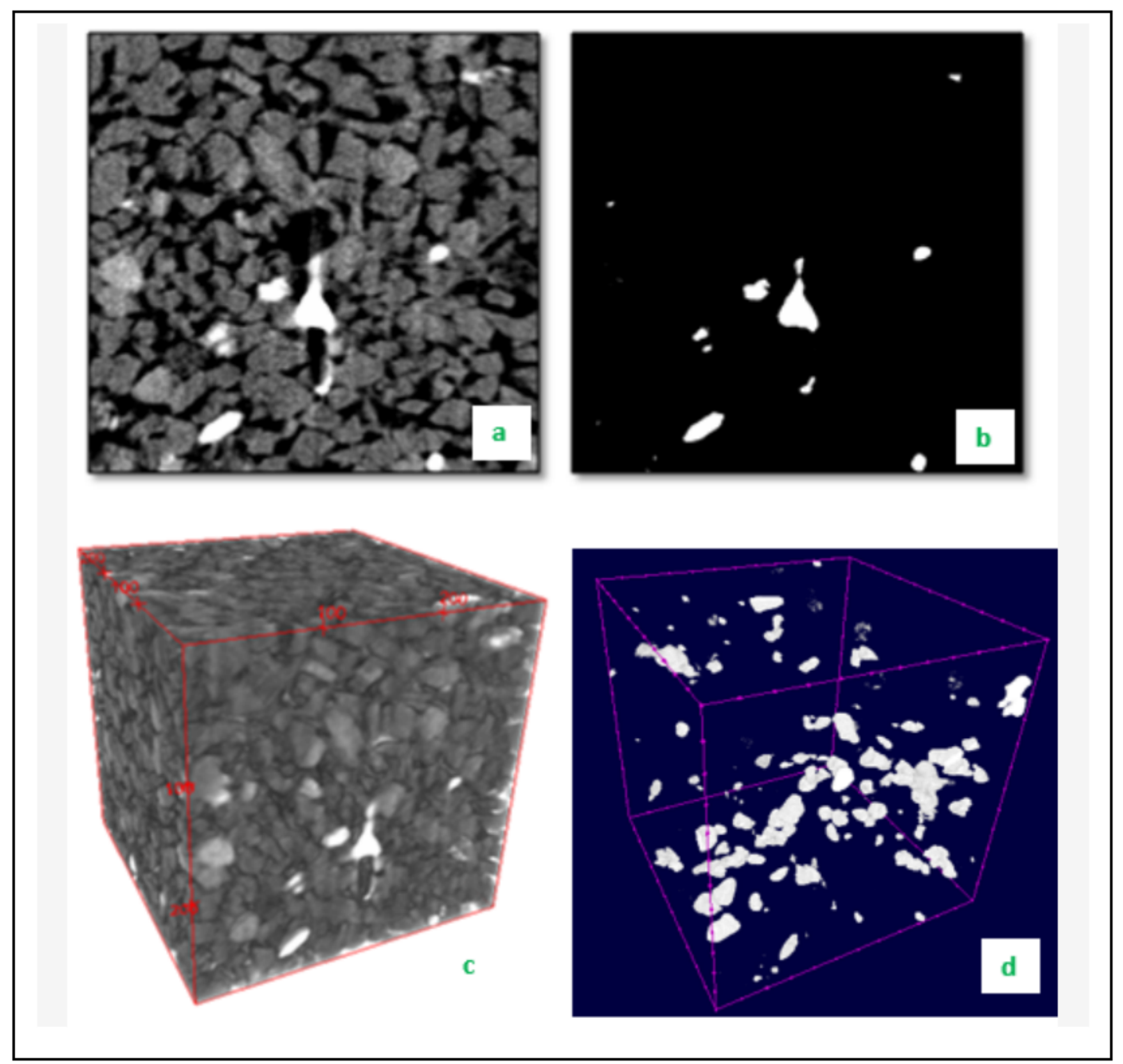

Gambar 4. Hasil pengolahan citra digital sampel batupasir. (a) adalah citra digital original dari sampel, (b) adalah pemisahan mineral berdasarkan perbedaan densitas, (c) adalah hasil 3D dari Gambar (a), dan (d) adalah hasil 3D dari Gambar (b). 
Tabel 3. Hasil perhitungan nilai parameter fisis sampel batupasir.

\begin{tabular}{lcrrrr}
\hline Besaran & Laboratorium & Han (1986) & Raymer (1980) & Nur (1998) & Digital Rock Physics \\
\hline Porositas (\%) & 31,70 & 31,7 & 31,7 & 31,7 & 31,7 \\
Permeabilitas (mD) & 2800,00 & & & & 3073 \\
Modulus Bulk (GPa) & 4,08 & 12,06 & 7.30 & 6.69 & 7,79 \\
Modulus Shear (GPa) & 3,23 & 9,39 & 5.46 & 6.02 & 6,46 \\
$V_{p}(\mathrm{~km} / \mathrm{s})$ & 1,73 & 3,04 & 2,34 & 2,33 & 2,42 \\
$V_{s}(\mathrm{~km} / \mathrm{s})$ & 1,16 & 1,88 & 1,43 & 1,51 & 1,52 \\
$V_{p} / V_{s}$ & 1,49 & 1,62 & 1,63 & 1,54 & 1,59 \\
\hline
\end{tabular}

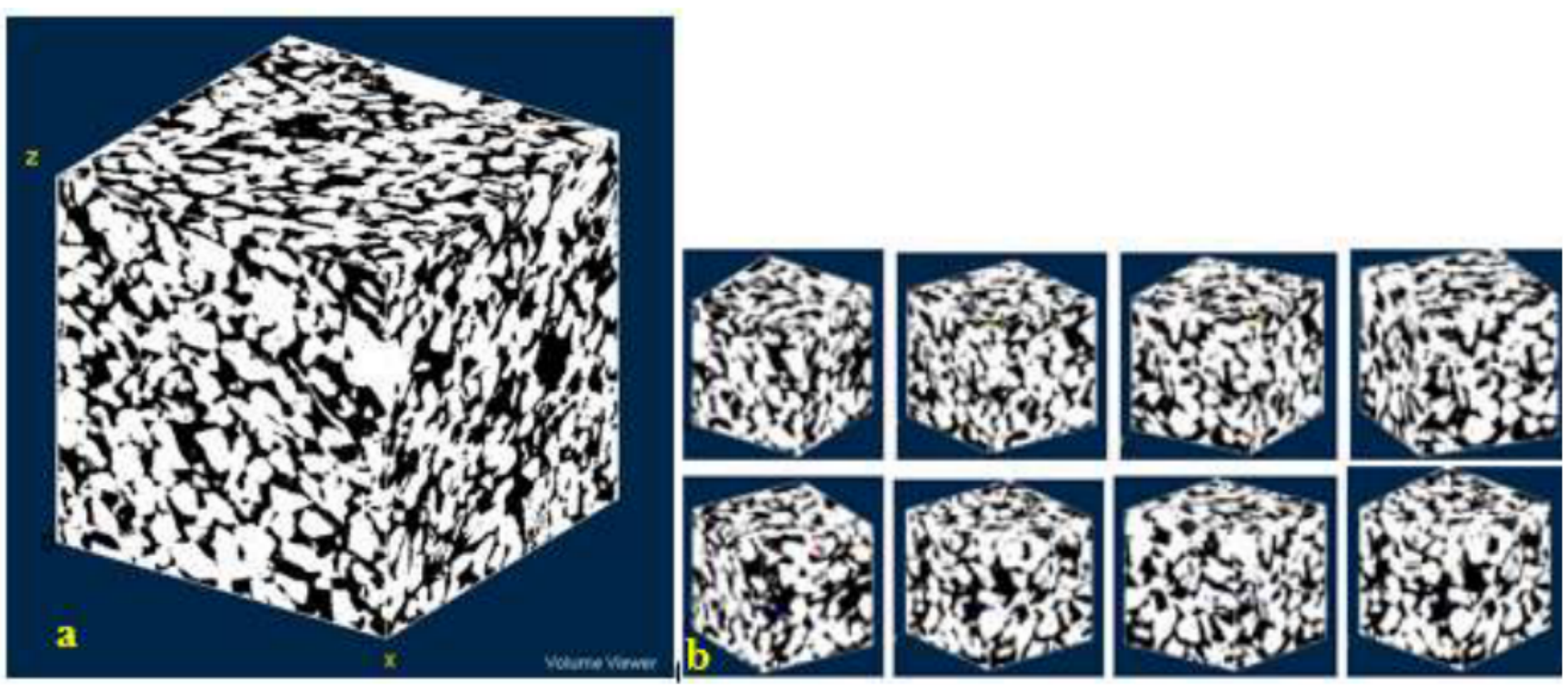

Gambar 5. Hasil citra digital sub-kubus yang dibuat dengan memecah kubus utama menjadi beberapa sub-kubus.

Tabel 4. Hasil perhitungan simulasi digital sampel batupasir pada tiap-tiap sub-kubus

\begin{tabular}{lcrrrrl}
\hline Sub Cube & Porositas & Permeabilitas $(\mathrm{MD})$ & $V_{p} \mathrm{~km} / \mathrm{s}$ & $V_{s}(\mathrm{~km} / \mathrm{s})$ & Modulus Shear $(\mathrm{GPa})$ & Modulus Bulk $(\mathrm{GPa})$ \\
\hline 1 & 0.241 & 1989 & 3.21 & 2.00 & 10.89 & 13.56 \\
2 & 0.211 & 824 & 3.47 & 2.16 & 12.72 & 15.82 \\
3 & 0.332 & 6420 & 2.49 & 1.55 & 6.52 & 8.15 \\
4 & 0.159 & 160 & 3.94 & 2.46 & 16.42 & 20.41 \\
5 & 0.287 & 2809 & 2.84 & 1.76 & 8.47 & 10.56 \\
6 & 0.263 & 5022 & 3.03 & 1.89 & 9.67 & 12.06 \\
7 & 0.302 & 3760 & 2.86 & 1.69 & 7.78 & 9.71 \\
8 & 0.284 & 835 & 3.44 & 1.78 & 8.62 & 10.74 \\
9 & 0.215 & 5820 & 2.53 & 1.58 & 12.45 & 15.50 \\
10 & 0.326 & 3195 & 2.94 & 1.83 & 6.76 & 8.44 \\
11 & 0.274 & 486 & 3.50 & 2.18 & 9.10 & 11.34 \\
12 & 0.208 & 4350 & 2.77 & 1.73 & 12.90 & 16.05 \\
13 & 0.295 & 380 & 3.68 & 2.29 & 8.10 & 10.11 \\
14 & 0.188 & 2459 & 3.11 & 1.94 & 14.27 & 17.74 \\
15 & 0.253 & 867 & 3.34 & 2.08 & 10.21 & 12.72 \\
16 & 0.226 & & & & 11.75 & 14.63 \\
\hline
\end{tabular}

sampel batuan yang memiliki ukuran sama dengan di alam, kita dapat memprediksi nilai parameter fisis batuan dengan ketelitian baik sehingga mendekati nilai sebenarnya di alam.

\section{KESIMPULAN}

Kesimpulan dari penelitian ini adalah (1) -CT image mampu memvisualisasikan struktur mikro batuan seperti pori dan kepadatan matriks, (2) -CT gambar dikombinasikan dengan perhitungan digital mampu memberikan hasil visualisasi pori , porositas nilai prediksi, nilai prediksi permeabilitas, fraksi matriks kepadatan batu tinggi-rendah, dan 


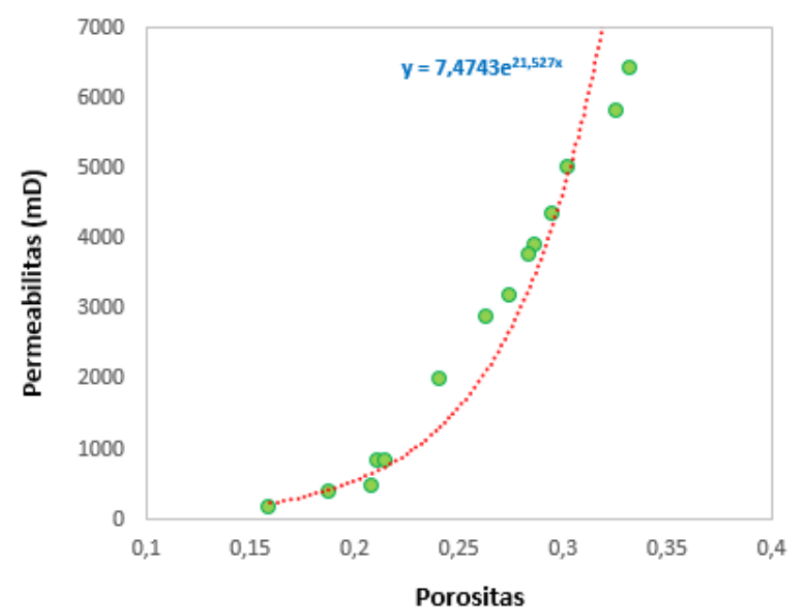

Gambar 6. Variasi nilai permeabilitas yang dipengaruhi oleh nilai permeabilitas.

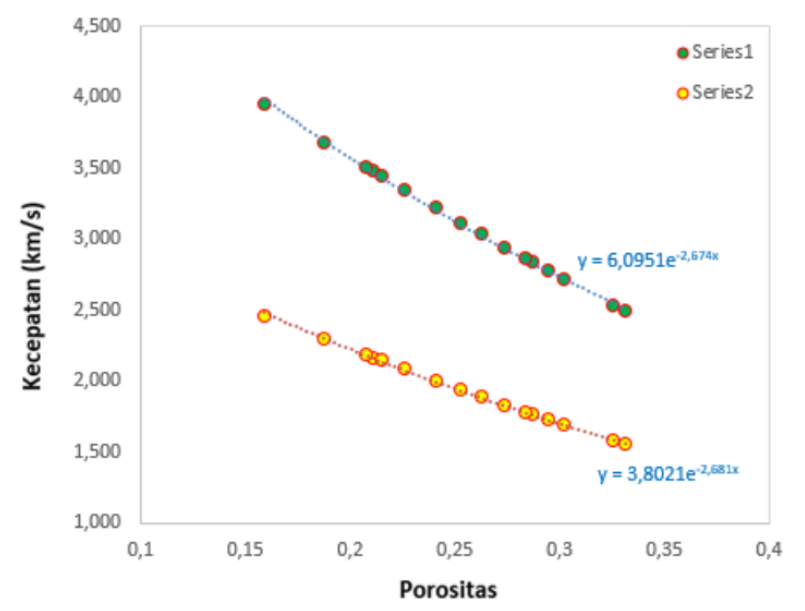

Gambar 7. Variasi nilai kecepatan gelombang seismik pada sampel batupasir.

elastisitas sampel batu pasir, (3) metode ini dikombinasikan dengan fisika batuan dapat menjadi metode yang praktis untuk menentukan sifat batuan dari fragmen batuan kecil (mikroskopis).

\section{UCAPAN TERIMA KASIH}

Ucapan terima kasih disampaikan kepada PT Pertamina atas bantuan berupa data inti core sampel batupasir dan kepada pihak GeoDict (Jerman) atas izin penggunaan free trial software GeoDict.

\section{DAFTAR PUSTAKA}

Andra, H., Combaret N., Dvorkin J., Glatt E., Han J., Krzikalla F., Lee M., Madonna C., Marsh M., Mukerji T., Ricker S., Saenger E.H., Sain R., Saxena N., Wiegmann A. dan Zhan X., 2013. Digital Rock Physics Benchmarks-Part I: Imaging and Segmentation. Journal Computers \& Geosciences, ELSEVIER 50 25-32.
Arns, C.H., Knackstedt, M.A., 2002. Computation of Linear Elastic Properties from Microtomographic Images: Methodology and Agreement Between Theory and Experiment. Journal of Geophysics, Vol. 67, No. 5, 1396-1405.

Fourier, D.E.L., 2014. Analysis of Permeability and Tortuosity of Fontainebleau Sandstone and Its Models Using Digital Rock Physics Approach. Physics of Earth and Complex System, Faculty of Mathematics and Natural Sciences, Bandung Institute of Technology, Indonesia.

Handoyo., Fatkhan., Fourier, D.E.L., 2014. Digital Rock Physics Application: Structure Parameters Characterization, Materials Identification, Fluid Modeling, and Elastic Properties Estimation of Saturated Sandstones. HAGI Proceeding 2014 Solo, Bandung Institute of Technology, Indonesia.

Mavko, G., dan Nur, A., 1999. The Rock Physics Handbook, Second Edition Tools for Seismic Analysis of Porous Media. Cambridge University Press The Edinburgh Building, Cambridge CB2 8RU, UK

Sukmono, S. 2002. Seismic Inversion and AVO Analysis for Reservoir. Program Studi Teknik Geofisika ITB. Bandung. Indonesia.

Raymer, L.L., Hunt, E.R., dan Gardner, J. S., 1980. An improved sonic transit time-to-porosity transform. Trans. Soc. Prof. Well Log Analysts, 21st Annual Logging Symposium, Paper P.

R. Sungkorn, A. Morcote, G. Carpio, G. Davalos, Y. Mu, A. Grader, N. Derzhi, J. Toelke, 2015. Multi-Scale And Upscaling Of Digital Rock Physics With A Machine That Can Learn About Rocks. Ingrain Inc., 3733 Westheimer Rd., Houston, Texas, 77027, U.S.A.

Wiegman, 2012. Predicting Effective Elastic Properties with Elastodict, Fraunhofer ITW Germany. 